\title{
Hawk $^{\circledR}$ JAWS versus Lumenis $^{\circledast}$ VersaCut prostate morcellation devices: A comparative study and comprehensive literature review
}

\author{
Hawk ${ }^{\circledR}$ JAWS ve Lumenis ${ }^{\circledR}$ VersaCut prostat morselasyon cihazları: Karșıllaștırmalı bir çalıșma \\ ve kapsamlı literatür incelemesi

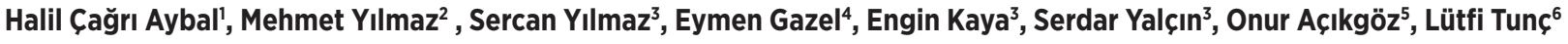 \\ 1 Kahramankazan Hamdi Eris State Hospital, Department of Urology, Ankara,Turkey \\ 2 University of Freiburg-Medical Centre, Faculty of Medicine, Department of Urology, Freiburg, Germany \\ 3 University of Health Sciences, Gülhane Training and Research Hospital, Department of Urology, Ankara, Turkey \\ 4 Acıbadem University Ankara Hospital, Department of Urology, Ankara, Turkey \\ 5 Pendik State Hospital,Department of Urology, Istanbul,Turkey \\ 6 Gazi University Faculty of Medicine, Department of Urology, Ankara, Turkey
}

\begin{tabular}{|c|c|}
\hline \multicolumn{2}{|c|}{ 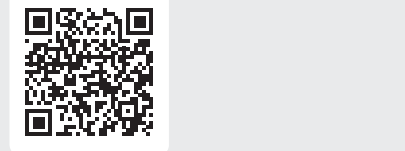 } \\
\hline \multicolumn{2}{|c|}{ Submitted (Geliş tarihi): 2021-05-26 } \\
\hline \multicolumn{2}{|c|}{ Accepted (Kabul tarihi): 2021-10-13 } \\
\hline \multicolumn{2}{|c|}{ Correspondence / Yazışma } \\
\hline \multicolumn{2}{|c|}{ Mehmet Yılmaz } \\
\hline \multicolumn{2}{|c|}{ Department of Urology, Faculty of } \\
\hline \multicolumn{2}{|c|}{ Medicine, Medical Centre- University of } \\
\hline \multicolumn{2}{|c|}{ Freiburg, Hugstetter Str. 55, } \\
\hline \multicolumn{2}{|c|}{79106 Freiburg, Germany } \\
\hline \multicolumn{2}{|c|}{ Email:mehmet.yilmaz@uniklinik-freiburg.de } \\
\hline \multicolumn{2}{|c|}{ Tel: +49 $761270-25820$} \\
\hline \multicolumn{2}{|c|}{ Fax: $+49761270-28960$} \\
\hline \multicolumn{2}{|c|}{ ORCID } \\
\hline H.Ç.A. & 0000-0001-9123-6139 \\
\hline M.Y. & 0000-0003-3774-9982 \\
\hline S.Y. & 0000-0001-6820-6708 \\
\hline E.G. & 0000-0002-6483-9249 \\
\hline E.K. & $0000-0002-5272-572 \mathrm{X}$ \\
\hline S.Y. & $0000-0003-4586-7591$ \\
\hline O.A. & $0000-0001-9821-4362$ \\
\hline L.T. & $0000-0002-7338-3909$ \\
\hline (c) (1) \$ & \\
\hline This wo & licensed under a Creative \\
\hline $\begin{array}{l}\text { Commo } \\
4.0 \text { Inter }\end{array}$ & $\begin{array}{l}\text { tribution-NonCommercial } \\
\text { onal License. }\end{array}$ \\
\hline
\end{tabular}

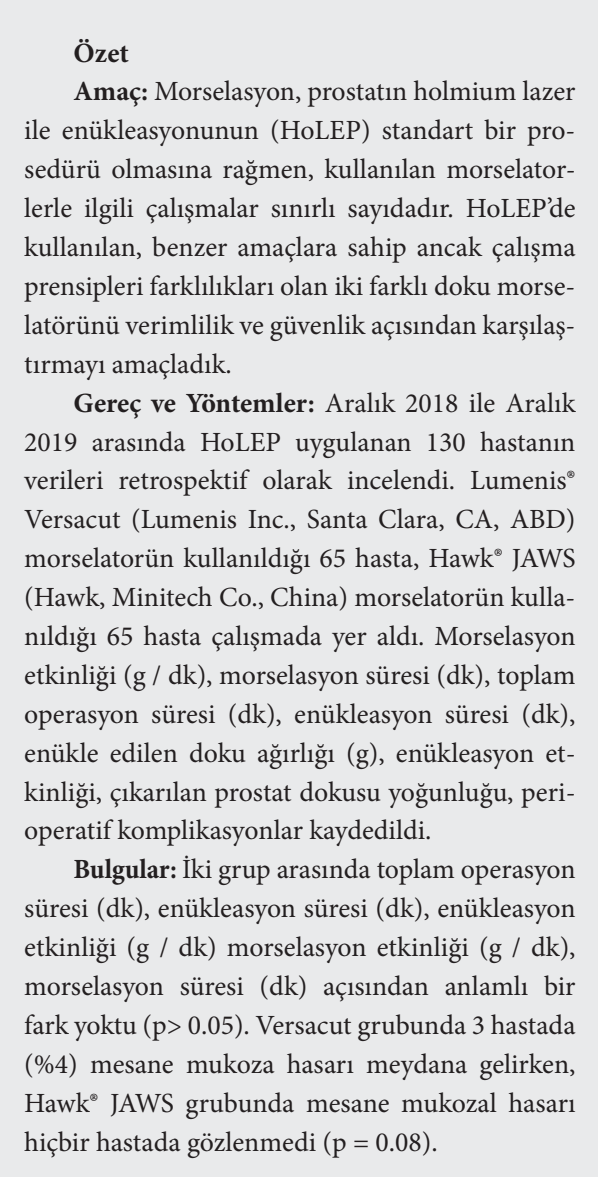

Abstract

Objective: Although morcellation is a standard procedure of Holmium Laser Enucleation of the Prostate (HoLEP), studies on the morcellators used are limited in number. We aimed to compare two different tissue morcellators used in HoLEP, which have similar objectives but differences in efficiency and safety in working principles.

Material and Methods: The data of $130 \mathrm{pa}-$ tients who underwent HoLEP between December 2018 and December 2019 were retrospectively reviewed. Sixty-five patients received Lumenis ${ }^{\circ}$ Versacut (Lumenis Inc., Santa Clara, CA, USA) morcellator and 65 patients received Hawk ${ }^{\circ}$ JAWS (Hawk, Minitech Co., China) morcellator after enucleation were included in the study. The efficiency of morcellation $(\mathrm{g} / \mathrm{min})$, morcellation time (min), total operation time ( $\mathrm{min}$ ), enucleation time ( $\mathrm{min}$ ), enucleated tissue weight ( $\mathrm{g}$ ), the efficiency of enucleation, densities of the removed prostate tissues, perioperative complications associated with the use of a morcellator were recorded perioperatively.

Results: There was no significant difference in total operation time (min), enucleation time (min), enucleated tissue weight (g), and efficiency of enucleation $(\mathrm{g} / \mathrm{min})$ efficiency of morcellation, morcellation time ( $\mathrm{min}$ ) between the two groups. Bladder mucosal damage occurred in 3 patients (4\%) in the Versacut group, while mucosal bladder

Cite As: Aybal HÇ, Yllmaz M, Yllmaz S et al. Hawk ${ }^{\circ}$ JAWS versus Lumenis ${ }^{\circ}$ VersaCut prostate morcellation devices: A comparative study and comprehensive literature review. New J Urol. 2022;17(1):6-13. DOI: 10.33719/yud.2022;17-1-943412 
Sonuç: Hawk ${ }^{\oplus}$ JAWS ve Lumenis ${ }^{\bullet}$ VersaCut morselatorleri, verimlilikleri ve güvenlik profilleri açısından karşılaştırılabilir sonuçlara sahiptir.

Anahtar Kelimeler: Hawk, HoLEP, morselasyon, morselator, Versacut. damage was not observed in any patient in the Hawk ${ }^{\circ}$ JAWS group $(\mathrm{p}=0.08)$.

Conclusion: Hawk ${ }^{\bullet}$ JAWS and Lumenis ${ }^{\circ}$ VersaCut morcellators were comparable in their efficiency and safety.

Keywords: Hawk, HoLEP, morcellation, morcellator, Versacut.

\section{INTRODUCTION}

Endoscopic enucleation of the prostate by using laser has become popular in recent years in the surgical treatment of benign prostatic obstruction (BPO). Holmium Laser Enucleation of the Prostate (HoLEP) method employing enucleation and mechanical morcellator was first described by Gilling and Fraundorfer in 1998 (1). It has been demonstrated in randomized studies with long follow-up periods that HoLEP, performed using Holmium laser, could also be performed in large prostates $>100 \mathrm{~g}$ (2). HoLEP has come into prominence as an alternative minimally invasive prostate surgery in terms of efficiency, safety, and complications to TUR P and open prostatectomy (3-5). HoLEP is now among the top options in the guidelines for the surgical treatment of $\mathrm{BPO}$ as a result of the satisfactory results obtained in studies conducted with large series $(6,7)$.

HoLEP surgery has two basic steps: Enucleation and morcellation $(8,9)$. HoLEP studies in the literature mostly focus on enucleation and its techniques. Although morcellation is a standard procedure of HoLEP and the step that entails the highest risk of complications, studies on morcellation and morcellators used are limited in number $(8,10,11)$. The importance of morcellation has become evident as it is a variable that directly affects the duration of surgery and, thus, anaesthesia, especially in patients with a large prostate. Accordingly, studies have started for fast and safe morcellators, and different types of morcellators from many brands have been introduced to the market. Research and development studies on this subject are still ongoing.

This study aimed to compare two different tissue morcellators used in HoLEP surgery, which have similar objectives but differences in efficiency and safety in working principles.

\section{MATERIAL AND METHODS}

The approval was obtained by the Institutional Review Board of Gazi University Faculty of Medicine (No: 2020-04). Informed consent was obtained from all men. This study was conducted following the Helsinki Declaration. The data of 130 patients who underwent HoLEP between December 2018- December 2019 were retrospectively reviewed. Age, body mass index (BMI) $(\mathrm{kg} / \mathrm{m} 2)$, hemoglobin $(\mathrm{Hb})$, prostate-specific antigen (PSA) levels, prostate volume measured by transabdominal ultrasonography were obtained. International Prostate Symptom Score total (IPSS- T), IPSS storage (IPSS- S) and voiding (IPSS- V), mean maximal urinary flow rate ( $\mathrm{Qmax})$, postvoiding residual volume (PVR) were recorded. All patients received alpha-blocker medication for at least 6 months before surgery. Inclusion criteria for HoLEP surgery were; failure of medical treatment, Qmax $\leq 15 \mathrm{ml} / \mathrm{s}$, IPSS-T $\geq$ $8, \mathrm{PVR} \geq 50 \mathrm{ml}$. Patients with a history of previous BPO surgical treatment, prostate or bladder cancer, neurogenic bladder, urethral strictures, and patients with a history of using 5-alpha reductase inhibitor were excluded from the study.

The efficiency of morcellation (enucleated prostate weight/morcellation time, morcellation time ( $\mathrm{min}$ ), total operation time ( $\mathrm{min}$ ), enucleation time ( $\mathrm{min}$ ), enucleated tissue weight $(\mathrm{g})$, the efficiency of enucleation (enucleated prostate weight/enucleation time) ( $\mathrm{g} / \mathrm{min}$ ), densities of the removed prostate tissues and perioperative complications associated with the use of a morcellator were recorded perioperatively. The technique for prostatic tissue density measurement has been previously described (12). Catheterization time (hours) and hospitalization time (hours) were recorded postoperatively. 


\section{Surgical Technique}

A 26-Fr continuous flow laser resectoscope for each patient, a laser-fibre stabilizing bridge, a $120 \mathrm{~W}$ holmium laser (VersaPulse; Lumenis Ltd., Israel), a 550$\mu \mathrm{m}$ end-firing laser fibre (SlimLine; Lumenis Ltd.), and a 26-Fr nephroscope was used. For the morcellation step, 65 patients received Lumenis ${ }^{\oplus}$ Versacut (Lumenis Inc., Santa Clara, CA, USA) morcellator and 65 patients received Hawk ${ }^{\oplus}$ JAWS (Hawk, Minitech Co., China) morcellator after enucleation were included in the study (Suppl-1). The blade system of the morcellators was renewed after each 100 gr tissue morcellation.

All patients were operated on using the "Omega Sign" technique, a HoLEP technique described earlier (13). The operations were performed by a single surgeon (LT) with HoLEP experience of over 500 cases (14). During the morcellation phase, the continuous flow was provided with 4 units of 3-liter physiological saline solutions, and bladder distension was achieved by closing the drain. In addition, an assistant doctor stood by the patient and constantly checked the bladder fullness until the end of the procedure.

\section{Statistical Analysis}

The Statistical Package for Social Sciences 23.0 software (SPSS 23.0, Chicago, USA) was used for the statistical analysis. The Kolmogorov-Smirnov, Kurtosis, and Skewness Tests were used to assess the data normality. The clinical characteristics of the two groups were compared with Mann-Whitney U or Student t-test for continuous variables and with the Fisher's Exact or
Pearson Chi-Square test for categorical variables. All statistical tests were two-sided, and the $p<0.05$ value was considered statistically significant.

\section{RESULTS}

Table 1 presents main preoperative characteristics of the patients. Preoperative parameters including patient age (years), PSA ( $\mathrm{ng} / \mathrm{mL}), \mathrm{BMI}(\mathrm{kg} / \mathrm{m} 2), \mathrm{Hb}$ level $(\mathrm{g} / \mathrm{dL})$, prostate volume $(\mathrm{mL})$, IPSS pre-V, IPSS pre-S, IPSS-Total, Qmax $(\mathrm{ml} / \mathrm{s})$ and PVR $(\mathrm{mL})$ were similar between two groups.

Table 2 presents the postoperative surgical results of the patients. No significant difference was found in postoperative $\mathrm{Hb}$ levels, prostatic tissue density $(\mathrm{g} / \mathrm{mL})$, $\mathrm{Hb}$ decrease ( $\mathrm{g} / \mathrm{dL}$ ), catheterization time (hours), and hospitalization time(hours) between the two groups.

Table 3 presents the perioperative results. There was no statistically significant difference in total operation time ( $\mathrm{min}$ ), enucleation time ( $\mathrm{min})$, enucleated tissue weight $(\mathrm{g})$, and efficiency of enucleation $(\mathrm{g} / \mathrm{min})$ efficiency of morcellation, morcellation time (min) between the two groups.

Table 4 presents the comparison of perioperative complications due to morcellator use between groups. Intraperitoneal or extraperitoneal bladder perforation did not occur in any patient in either group. Bladder mucosal damage occurred in 3 patients (4\%) in the Versacut group, while mucosal bladder damage was not observed in any patient in the JAWS group, and the difference was not statistically significant $(p=0.08)$.

Table 1. Baseline characteristics and preoperative data of the patients

\begin{tabular}{llll}
\hline Variables & Lumenis $^{\odot}$ Versacut (N:65) & Hawk $^{\circledR}$ JAWS (N: 65) & P Value \\
\hline Patient age (year) & $65 \pm 6.53$ & $64 \pm 6.86$ & 0.41 \\
PSA (ng/mL) & $2.53 \pm 11.62$ & $2.4 \pm 11.92$ & 0.28 \\
BMI & $24.8 \pm 2.77$ & $24.6 \pm 3.04$ & 0.9 \\
Hb level (g/dL)* & $14.6 \pm 1.11$ & $14.6 \pm 1.08$ & 0.41 \\
Prostate Volume (mL) & $84.71 \pm 41.54$ & $65.01 \pm 37.46$ & 0.6 \\
IPSS pre-Voiding & $15 \pm 3.22$ & $15 \pm 3.72$ & 0.6 \\
IPSS pre-Storage & $11 \pm 1.67$ & $11 \pm 1.66$ & 0.54 \\
IPSS Total & $26 \pm 3.36$ & $27 \pm 4.1$ & 0.66 \\
Qmax (ml/s) & $7.8 \pm 3.03$ & $7.9 \pm 2.48$ & 0.38 \\
PVR (ml) & $139 \pm 78.06$ & $134 \pm 73.06$ & 0.96 \\
\hline
\end{tabular}

N: number of patients; SD: Standart Deviation; PSA: Prostat Spesific Antigen; Hb: hemoglobin; BMI: Body mass index; IPSS: International ProstateSymptom Score; Qmax: maximum velocity at voiding; PVR: Post Voiding Residue; S: second.

* Statistically analyzed with Student $t$ test; others analyzed with Mann Whitney U test 
Table 2. Comparison of the postoperative outcomes of the patients

\begin{tabular}{llll}
\hline & Lumenis $^{\circledR}$ Versacut $^{(N: 65)}$ & Hawk $^{\circledast}$ JAWS (N:65) & P Value \\
\hline Prostatic tissue density ${ }^{\star}(\mathrm{g} / \mathrm{mL})$ & $1.03 \pm 0.07$ & $1.04 \pm 0.11$ & 0.44 \\
Postop Hb (g/dL) & $14.15 \pm 1.17$ & $14.15 \pm 1.07$ & 0.31 \\
Hb-decrease (g/dL) & $0.5 \pm 0.29$ & $0.5 \pm 0.27$ & 0.93 \\
Catheterization time (hour) & $19 \pm 3.53$ & $20 \pm 4.86$ & 0.26 \\
Hospitalization time (hour) & $23 \pm 3.32$ & $23 \pm 4.27$ & 0.26 \\
\hline
\end{tabular}

N: number of patients; SD: Standart Deviation; Hb: hemoglobin.

* Statistically analyzed with Student $t$-test others analyzed with Mann Whitney U test.

Table 3. Comparison of perioperative outcomes between groups

\begin{tabular}{llll}
\hline & Lumenis $^{\circledR}$ Versacut (N: 65) & Hawk $^{\circledR}$ JAWS (N: 65) & P Value \\
\hline Enuclated tissue weight (g) & $45.31 \pm 27.28$ & $47.28 \pm 30.25$ & 0.59 \\
Efficiency of enucleation & $1.23 \pm 0.19$ & $1.23 \pm 0.22$ & 0.95 \\
Efficiency of morcellation & $4.1 \pm 0.69$ & $4.25 \pm 2.53$ & 0.1 \\
Enucleation time (min) & $52.2 \pm 28.62$ & $43.34 \pm 25.37$ & 0.85 \\
Morcelation time (min) & $10.63 \pm 6.59$ & $9.85 \pm 6.44$ & 0.34 \\
Total operation time (min) & $70.7 \pm 32.8$ & $61.07 \pm 28.44$ & 0.55 \\
\hline
\end{tabular}

* Statistically analyzed with Mann Whitney $U$ test

Table 4. Comparison of perioperative outcomes between groups

\begin{tabular}{llll}
\hline Complications & Lumenis $^{\oplus}$ Versacut n(\%) (N:65) & Hawk $^{\oplus}$ JAWS n(\%) (N:65) & P Value \\
\hline Device Problem & $1(1.5)$ & 0 & 1 \\
\hline Mucosa damage $^{\star}$ & $3(4)$ & 0 & 0.08 \\
\hline
\end{tabular}

*Statistically analyzed with Pearson Chi-Square test; others analyzed with Fisher's Exact test

Patients with mucosal damage were discharged with a catheter (it did not affect hospitalization time), and their catheters were kept for 3 days. Device problem was observed in 1 patient (1.5\%) only in Group 1, and there was no statistically significant difference between groups.

\section{DISCUSSION}

Prostate enucleation techniques have been developed and modified with the introduction of HoLEP in urology practice (15). The morcellation step is common in all of the HoLEP techniques described so far, and the basic principle is the same in all techniques except for the morcellators used. According to our literature review, no studies are comparing Hawk ${ }^{\circledR}$ JAWS and Lumenis ${ }^{\oplus}$ VersaCut morcellators in terms of efficiency and safety profile in HoLEP. In that respect, our study is the first in the literature.

Morcellation can be defined as dividing a large tissue sample into smaller pieces to facilitate tissue extraction as a result of surgery (16). In the morcellation step, the last step of HoLEP, free prostate tissue pushed into the bladder following enucleation is taken out in small pieces. The tissue morcellators used in this pro- 
cess are designed to perform suction (aspiration) and tissue cutting $(8,17)$. The suction removes the morcellated tissues out of the bladder while keeping the tissue close to the blade, and the movable blade of the morcellator breaks the prostatic adenoma tissue into small fragments. The efficiency of the morcellator and possible complications depend on suction pressure and cutting mechanism. The bladder should be kept constantly distended to avoid possible bladder injuries during the morcellation process. We aimed to minimize possible complications during the procedure by performing bladder control during morcellation with the help of a bedside assistant doctor.

Today, there are three popular prostate tissue morcellators commonly used following prostate enucleation. These include VersaCut (Lumenis Inc., Santa Clara, USA), Piranha (Richard Wolf Inc., Knittlingen, Germany), and DrillCut (Karl Storz Inc., Tuttlingen, Germany) morcellators $(18,19)$. The differences between morcellators are mainly related to blade movements of the morcellator (reciprocating vs. oscillating) and the presence of teeth on the blade (non-toothed vs. toothed) $(8,10)$. The oscillating system has a rotating morcellator with a disposable jagged blade that oscillates alongside. The tip of the oscillating morcellator is blunt, and this tip does not move. Morcellator's blade is connected to a motor handle and connected to a generator, a suction pump, and a disposable tubing set (20). In the reciprocating system, the blade reaches beyond the end of the device while moving back and forth. This system works with a motor arm and a disposable tube attached to a cylinder pump to provide suction and does not require much effort for installation (20).

Piranha and DrillCut morcellators are oscillating and toothed, while VersaCut is a non-toothed and reciprocating morcellator $(18,19)$. Hawk $\mathrm{k}^{\bowtie}$ morcellators used in the present study are toothed and oscillating morcellators. Most studies on morcellators in the literature are about Piranha and VersaCut morcellators. In a retrospective study, morcellation time with Piranha morcellator was found to be shorter, and morcellation efficiency was almost twice that of VersaCut $(8.6 \mathrm{~g} / \mathrm{min}$ vs. $3.8 \mathrm{~g} / \mathrm{min} ; \mathrm{p}<0.0001)(20)$. Elshal et al. similarly showed that the morcellation efficiency of the Piranha morcellator was higher than that of the VersaCut morcellator (8). Rivera et al. also demonstrated that the morcellator efficiency of Piranha was higher than that of VersaCut (4.4 vs. $7.0 \mathrm{~g} / \mathrm{min}, \mathrm{p}<0.01$ ) (21). In a randomized prospective study by El Tayeb et al., the morcellation efficiency of Piranha was higher than that of VersaCut; however, the difference was not statistically significant (22). In contrast to these studies, VersaCut had a shorter morcellation time (9.8 min vs. $14.5 \mathrm{~min}$ ) and higher morcellation efficiency than Piranha ( $8.4 \mathrm{~g} /$ min vs. $4.7 \mathrm{~g} / \mathrm{min}$ ) in another study (17). In a study comparing the efficiency and reliability of DrillCut and VersaCut morcellators, there was no significant difference between their morcellation times; however, it was found that the efficiency of VersaCut morcellator was significantly higher (3.6 vs. $4.9 \mathrm{~g} / \mathrm{min} ; \mathrm{p}=0.03$ ) (20).

The number of studies in the literature reporting the efficiency of Hawk morcellator is limited. In a study conducted by He et al., HoLEP was performed in 63 patients, and a Hawk morcellator was used for morcellation. Similar to our results, morcellation efficiency was $5.4 \pm 2.9 \mathrm{~g} / \mathrm{min}$, and morcellation time was $11.2 \pm 3.9$ min in that study (23). Morcellation time has been previously shown to positively correlate with prostatic tissue density $(\rho=0.272, p=0.0005)(12)$. As there is no difference between the prostate densities between the groups, we believe it provides more accurate comparisons of morcellation efficiency and morcellation time in our study.

Bladder injury is the most likely and important complication during morcellator use. Injuries may occur if the bladder is not sufficiently full during morcellation or if the endoscopic view during the operation is suboptimal (17). While superficial injuries can be managed by leaving the urethral catheter for a longer time, deeper and full-thickness bladder perforations may require open surgical repair (24). Bladder mucosal injury during HoLEP has been reported at a rate of $0.7-5.7 \%$ and bladder perforation at a rate of $0.1-1.5 \%$ $(8,22,25)$ in the literature. Ibrahim et al. observed no 
significant difference between DrillCut and VersaCut morcellators regarding complication rates, although the rate was higher for VersaCut $(2.4 \%$ vs. $7.3 \%$; $=$ $0.1)$ (19). While mucosal bladder injury occurred in $2(4.8 \%)$ patients during the use of VersaCut and in 1 (2.4\%) patient during the use of DrillCut, only one patient had bladder perforation requiring open surgical repair after the use of VersaCut (19). Intraperitoneal or extraperitoneal bladder perforation did not occur in any patient in either group in the present study.

Maheshwari et al. compared Piranha and VersaCut morcellators, and no patient in the Piranha group had perforation including the bladder muscle, whereas in the VersaCut group, three patients had deep bladder muscle injury, and none of the patients had bladder rupture (17). The incidences of bladder mucosal injury, deep muscle injury and bleeding requiring electrocoagulation were statistically significantly lower in the Piranha group (17). In another study, no bladder perforation occurred in Piranha or VersaCut groups, while one patient in the VersaCut group had superficial bladder mucosal injury (20). Elshal et al. observed bladder mucosa injury at a rate of $9 \%$ with VersaCut, while bladder mucosal injury or perforation was not observed with Piranha, and the difference was statistically significant $(p=0.01)(8)$. In a study that Zhang et al. performed diode laser prostatic enucleation and used Hawk morcellator, no perioperative bladder injury occurred in any patient (26). In a study by $\mathrm{He}$ et al. comparing HoLEP and diode laser enucleation, a Hawk morcellator was used in all patient groups, and no bladder injury, perforation, or injury in the urethral orifices were observed in any groups (23). In a more recent study in which Hawk morcellator was used after prostatic enucleation, no bladder injury occurred in any patient (27). In a study in which Thulium laser enucleation of the prostate and resection were compared, and Hawk morcellator was used, mucosal bladder injury was observed in 3 patients (1.6\%) in the enucleation group in which a morcellator was used; however, no statistically significant difference was found between groups $(\mathrm{p}=0.065)$. In the present study, bladder mucosa damage occurred in 3 patients (4\%) in the VersaCut group, while it was not observed in any patient in the Hawk group, and the difference was not statistically significant $(p=0.08)$. In studies in the literature, the morbidity associated with VersaCut has ranged from 0 to $9.1 \%$, while morbidity with Piranha is at a rate of $0-2.4 \%(8,18,20,22)$. In the present study, complications were observed at a rate of $5.5 \%$ in the Versacut group. Surgeons' experience, dual water use, and bladder distension control may be the factors that led to the low complication rate in the present study.

During the use of a morcellator, mechanical failures related to the morcellator may also occur. Ibrahim et al. reported that DrillCut morcellator failure occurred in $9.7 \%$ of the cases (19). In the literature, it was observed that VersaCut morcellator failed at a rate of $0-9.1 \%$, while Piranha morcellator failed in $0-2.7 \%$ of the cases $(8,19,20,22)$. In the present study, morcellator failure occurred in 1 patient (1.5\%) in the VersaCut group, while no failure occurred in the Hawk group, and no statistically significant difference was found between groups.

Our study has certain limitations to be stated. First, the number of patients in study groups is small, and the study is retrospective in nature. Secondly, the fact that morcellators have not been compared in terms of cost analysis. Thirdly, the learning curves of the morcellators have not been analyzed, and this may be considered one of the limitations of the present study.

\section{CONCLUSION}

Morcellation is an important step in HoLEP surgery and should be considered regarding complications. We showed that Hawk ${ }^{\circledR}$ JAWS and Lumenis ${ }^{\circledR}$ VersaCut morcellators were comparable in their efficiency and safety. The present study will contribute to the literature since scientific data about the morcellation step and morcellator equipment are limited.

\section{Conflict of interest}

The authors declare to have no conflicts of interest.

\section{Financial Disclosure}

The authors declared that this study has received no financial support. 


\section{Informed Consent}

Informed consent was obtained from all individual participants included in the study.

\section{Ethical Approval}

The study was approved by the Institutional Review Board of Gazi University Faculty of Medicine (No: 2020-04) and written informed consent was received from all participants. The study protocol conformed to the ethical guidelines of the Helsinki Declaration.

\section{Supplementary Material}

Accompanying video can be found on YouTube (Clip: Morcellation with Versacut and Hawk devices https://youtu.be/tQvJ7gOB1Co) and also be accessed by scanning QR code in below:

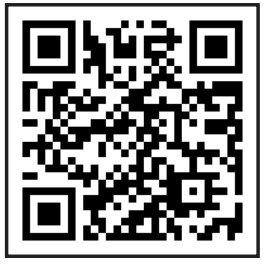

Suppl-1: Morcellation with Versacut and Hawk devices

\section{Author Contributions}

Conception and design; HÇA, SY, LT, Data acquisition; MY, SY, EK, OA, Data analysis and interpretation; HÇA, MY, SY, EK, OA, LT, Drafting the manuscript; HÇA, MY, EK, Critical revision of the manuscript for scientific and factual content; HÇA, MY, SY, EG, EK, SY, OA, Statistical analysis; HÇA, EG, Supervision; SY, LT.

\section{REFERENCES}

1. Fraundorfer MR, Gilling PJ. Holmium:YAG laser enucleation of the prostate combined with mechanical morcellation: preliminary results. Eur Urol. 1998; 33(1):69-72.

2. Kuntz RM, Lehrich K, Ahyai SA. Holmium laser enucleation of the prostate versus open prostatectomy for prostates greater than 100 grams: 5-year follow-up results of a randomised clinical trial. Eur Urol. 2008; 53(1):160-166.

3. Rieken M, Ebinger Mundorff N, Bonkat G, Wyler S, Bachmann A. Complications of laser prostatectomy: a review of recent data. World J Urol. 2010; 28(1):53-62.
4. Vincent MW, Gilling PJ. HoLEP has come of age. World J Urol. 2015; 33(4):487-493.

5. Sivarajan G, Borofsky MS, Shah O, Lingeman JE, Lepor $\mathrm{H}$. The Role of Minimally Invasive Surgical Techniques in the Management of Large-gland Benign Prostatic Hypertrophy. Rev Urol. 2015; 17(3):140-149.

6. Foster HE, Dahm P, Kohler TS, et al. Surgical Management of Lower Urinary Tract Symptoms Attributed to Benign Prostatic Hyperplasia: AUA Guideline Amendment 2019. J Urol. 2019; 202(3):592-598.

7. Oelke M, Bachmann A, Descazeaud A, et al. EAU guidelines on the treatment and follow-up of non-neurogenic male lower urinary tract symptoms including benign prostatic obstruction. Eur Urol. 2013; 64(1):118-140.

8. Elshal AM, Mekkawy R, Laymon M, El-Assmy A, El-Nahas AR. Towards optimizing prostate tissue retrieval following holmium laser enucleation of the prostate (HoLEP): Assessment of two morcellators and review of literature. Can Urol Assoc J. 2015; 9(9-10):E618-625.

9. Lee SH, Choi JI, Moon KY, Na W, Lee JB. Holmium laser enucleation of the prostate: modified morcellation technique and results. Korean J Urol. 2012; 53(11):779-784.

10. Becker B, Orywal AK, Hausmann T, Gross AJ, Netsch C. A Prospective Randomized Study Comparing Disposable with Reusable Blades for a Morcellator Device. J Endourol. 2017; 31(3):314-319.

11. Cornu JN, Terrasa JB, Lukacs B. Ex vivo comparison of available morcellation devices during holmium laser enucleation of the prostate through objective parameters. J Endourol. 2014; 28(10):1237-1240.

12. Kaya E, Gazel E, Yalcin S, et al. The effect of prostatic tissue density on the perioperative outcomes of Holmium laser enucleation of prostate (HoLEP): a pilot study. World J Urol. 2020; 38(2):455-461.

13. Tunc L, Yalcin S, Kaya E, et al. The "Omega Sign": a novel HoLEP technique that improves continence outcomes after enucleation. World J Urol. 2021; 39(1):135-141.

14. Yalçın S, Yllmaz S, Gazel E, et al. Holmium laser enucleation of the prostate for the treatment of size-independent BPH: A single-center experience of 600 cases. Turk J Urol. 2020; 46(3):219-225.

15. Oh SJ. Current surgical techniques of enucleation in holmium laser enucleation of the prostate. Investig Clin Urol. 2019; 60(5):333-342. 
16. Taylan E, Sahin C, Zeybek B, Akdemir A. Contained Morcellation: Review of Current Methods and Future Directions. Front Surg. 2017; 4:15.

17. Maheshwari PN, Wagaskar VG, Maheshwari RP. Comparison of the efficiency and complications of Lumenis and Wolf morcellators after holmium laser enucleation of the prostate. Indian J Urol. 2018; 34(2):140-143.

18. Hodhod A, Oquendo F, Nour H, et al. The ex vivo and in vivo Characteristics of New DrillCutTM Prostate Morcellator after Holmium Laser Enucleation of the Prostate: A Pilot Study. Urol Int. 2019; 103(1):95-101.

19. Ibrahim A, Elhilali MM, Elkoushy MA, Andonian S, Carrier S. DrillCut(TM) vs VersaCut(TM) prostate tissue morcellation devices after holmium laser enucleation: A prospective, randomized controlled trial. Can Urol Assoc J. 2018; 13(8):266-270.

20. McAdams S, Nunez-Nateras R, Martin CJ, Cha S, Humphreys MR. Morcellation Efficiency in Holmium Laser Enucleation of the Prostate: Oscillating Morcellator Outperforms Reciprocating Morcellator With no Apparent Learning Curve. Urology. 2017; 106:173-177.

21. Rivera ME, Lingeman JE, Heinsimer K, York NE, Krambeck AE. A Survey of Morcellator Preference and Cost Comparison of the Lumenis VersaCut and Wolf Piranha Morcellators. Urology. 2018; 111:54-58.

22. El Tayeb MM, Borofsky MS, Paonessa JE, Lingeman JE. Wolf Piranha Versus Lumenis VersaCut Prostate Morcellation Devices: A Prospective Randomized Trial. J Urol. 2016; 195(2):413-417.
23. He G, Shu Y, Wang B, et al. Comparison of Diode Laser (980 nm) Enucleation vs Holmium Laser Enucleation of the Prostate for the Treatment of Benign Prostatic Hyperplasia: A Randomized Controlled Trial with 12-Month Follow-Up. J Endourol. 2019; 33(10):843-849.

24. Morozov A, Taratkin M, Kozlov V, et al. Retrospective Assessment of Endoscopic Enucleation of Prostate Complications: A Single-Center Experience of More Than 1400 Patients. J Endourol. 2020; 34(2):192-197.

25. Elkoushy MA, Elshal AM, Elhilali MM. Reoperation After Holmium Laser Enucleation of the Prostate for Management of Benign Prostatic Hyperplasia: Assessment of Risk Factors with Time to Event Analysis. J Endourol. 2015; 29(7):797-804.

26. Zhang J, Wang X, Zhang Y, et al. $1470 \mathrm{~nm}$ Diode Laser Enucleation vs Plasmakinetic Resection of the Prostate for Benign Prostatic Hyperplasia: A Randomized Study. J Endourol. 2019; 33(3):211-217.

27. Zhang J, Li J, Wang X, et al. Efficacy and Safety of 1470$\mathrm{nm}$ Diode Laser Enucleation of the Prostate in Individuals With Benign Prostatic Hyperplasia Continuously Administered Oral Anticoagulants or Antiplatelet Drugs. Urology. 2020; 138:129-133. 